\title{
Clinical applications of low-level laser therapy in reproductive medicine; A literature review
}

\author{
Soheila Borhani, M.D. ${ }^{1}{ }^{*}$, Reza Salman Yazdi, DCLS. ${ }^{2}$
}

1. NYU Langone Health, New York, USA.

2. Artin Clinical Laboratory, Tehran, Iran.

* Corresponding Author:

Soheila Borhani

NYU Langone Health,

550 First Ave., New York, NY 10016

email: Soheila.Borhani@nyumc.org

\begin{abstract}
Infertility affects approximately $15 \%$ of couples worldwide, an estimated $30 \%$ of which is related to male factor infertility. Application of low level laser therapy (LLLT) to improve fertility status is a rapidly growing discipline in medicine. Laser therapy triggers a variety of biological processes through interaction with primary cellular photoacceptors. The present review aims at evaluating the literature available in the MEDLINE/ PubMed on cellular and molecular mechanisms of photobiomodulation in the domains of reproductive and veterinary medicine. We primarily focused on the clinical application of laser treatment on seminal quality, in particular its role in promoting spermatozoa motility, as well as the role of phototherapy in modulating assisted reproduction (ART). Additionally, we investigated the strength of evidence in support of the positive impact of photobiomodulation on facilitating ART.
\end{abstract}

Key words: low-level laser therapy (LLLT); photobiomodulation; male infertility; sperm motility; assisted reproductive technology (ART) 


\section{Introduction}

Phototherapy with low-level laser which is referred to as photobiomodulation is a developing discipline in the medicine. Low-level laser therapy (LLLT) is implicated in a verity of biological processes through interaction with primary cellular photoacceptors and messengers [1]. The efficacy of LLLT is highly dependent on the irradiated tissues and cells as well as the specific irradiation parameters. There is numerous evidence regarding "in vitro" and "in vivo" effects of photobiomodulation on different medical conditions. In the dentistry area, low-level laser is applied to treat dentine hypersensitivity, periodontitis, and improving oral mucositis [2-4]. LLLT is also used for management of many dermatologic disorders including alopecia and telangiectasia [5, 6]. Additionally, the efficacy of laser phototherapy is approved for treatment of musculoskeletal and rheumatologic disorders [7, 8]. Of note, photobiomodulation is implicated in nerve regeneration, promoting of wound healing, and reduction in TNF- $\alpha$ levels as well as a consequent subsiding of inflammation along with acceleration of cellular proliferation [9-11].

Clinical applications of the LLLT on improving fertility status is a rapid growing decepline in medicine. Epidemiological studies estimate about $15 \%$ of couples are affected by infertility worldwide [12]. According to Agarwal et al. [13], at least thirty million men are infertile globally with the highest rates in Africa and Eastern Europe. Asthenospermia or attenuation of the motile spermatozoa to less than 50 percent is a significant contributing factor in the male infertility. Asthenospermia is a multifactorial disorder which mandates a diverse therapeutic approaches. There is considerable literature on therapeutic modalities leading to improving sperm motility including varicocelectomy [14], and dietary supplementation with some certain vitamins and antioxidants [15]. Furthermore, the potency of such compounds as aromatase inhibitors [16], pentoxifylline [17], thyroxin [18], and exogenous platelet activating factor [19] have been demonstrated in acceleration of sperm motility. Recent advances in the domain of assisted reproductive techniques provide a novel therapeutic approach to male factor infertility, and last but not least is the application of laser therapy to promote asthenospermia.

The present review aims to consolidate the literature available on the efficacy of low-level laser light in the treatment of infertility. Specifically, we evaluate the cellular and molecular mechanisms of photobiomodulation, and put the focus on the photo-stimulative effect of LLLT on spermatozoa and improving the seminal quality as well as its pivotal role in modulating the assisted reproductive techniques (ART). The resources included here are the relevant literature in the MEDLINE/ PubMed. We did not take the publication date and publication status, nor the manuscript language into consideration. The search strategy consisted of the keyword terms consisting of low-level laser therapy (LLLT), photobiomodulation, infertility, sperm motility, and assisted reproductive technology (ART). 


\section{Effect of photobiomodulation on seminal parameters}

Improving male factor infertility using low-level laser therapy is a discernable area in the field of reproductive medicine. Phototherapy has also been extensively administered in the veterinary medicine practice and livestock breeding. The underlying pathways of photobiomodulation are not well established. However, several studied addressed probable mechanisms regarding interaction of laser light and spermatozoa. Motility is one of the most significant characteristics of sperm, which is associated with fertilizing capability. The mitochondrial apparatus within the midpiece of spermatozoa provides required energy for movement of flagellum or tail [20]. Albuquerque-Pontes et al. [21] indicated that low-level laser irradiation could induce activity of cytochrome $\mathrm{C}$ oxidase (COX). The COX complex is part of the mitochondrial respiratory chain and plays a critical role in the electron transport cascade. Modulation of this certain cytochrome oxidase activity leads to enhanced oxidative phosphorylation or adenosine triphosphate (ATP) generation. This process subsequently augments the sperm motility. Likewise, another study evaluating the efficacy of laser on the cryopreserved ram sperm showed an increase in the COX Vmax values as well as the COX affinity for its substrate. These findings were consistent with enhanced ATP levels in the irradiated samples and improved sperm motility [22]. Additionally, Passarella et al. [23] reported that some certain NADH-linked reactions occurring in the mitochondria are stimulated and triggered through laser irradiation.

On the molecular level, LLLT is mediated in up-regulation of the genes coding for a number of mitochondrial enzymes. Specifically, the subunits which are involved in the complexes I and IV of electron transport chain and ATP synthase [24]. Ferraresi et al. [25] evaluated the mitochondrial membrane potential and demonstrated that phototherapy increased ATP synthesis in the myotubes. On a different note, Tafur et al. [26] declared that low-intensity laser interacts with the endogenous cellular redox mechanisms. This effect is mediated through photoexcitation of cytochrome $\mathrm{C}$ oxidase in the mitochondrial electron transport chain. Laser light facilitates electron transferring to oxygen molecules and production of the reactive oxygen species (ROS). These anions are categorized into three main types, namely superoxide, hydrogen peroxide, and hydroxyl radical. ROS are required for spermatozoa maturation or capacitation [27]. Also, low levels of ROS could relatively enhance the sperm acrosome reaction [28]. According to Shahar et al. [29] photobiomodulation resulted in a significant increase in the human sperm motility and capacitation toward activation of protein kinase A and sarcoma protein kinase, as well as production of reactive oxygen species.

Another aspect of photobiomodulation is the effect of irradiation on the intracellular calcium ion levels, and its fundamental impact on the sperm motility. Low-level laser therapy increases the calcium influx via cellular pumps. In this regard, $\mathrm{Na}^{+} / \mathrm{Ca}^{2+}$ exchanger and voltage-gated calcium channel regulate the optimal intracellular calcium concentrations [30]. Lubart et al. [31] reported that LLLT prevents calcium uptake by mitochondria of spermatozoa while enhancing the $\mathrm{Ca}^{2+}$ binding to sperm plasma membrane. On the other hand, laser light at higher doses causes an 
overload in the intracellular $\mathrm{Ca}^{2+}$ levels. Such a process leads to hyperactivation of the $\mathrm{Ca}^{2+}$ ATPase pump and exhausts the ATP reservoir of the cells. These reactions ultimately increase the intracellular osmotic pressure and degenerate the spermatozoa [32].

Effect of the laser therapy on the sperm parameters is directly related to the semen sample quality, irradiation methods, applied doses, wavelengths, and time intervals. As mentioned earlier on the role of laser irradiation in the cellular calcium regulation, spermatozoa react differently in response to various laser doses. This fact emphasizes the importance of selecting the optimal output power. A number of research studies compared the efficacy of LLLT on male infertility using different irradiation methods including a recent study conducted by our research group on the impact of $830 \mathrm{~nm}$ diode laser on human sperm motility [33]. We evaluated the semen specimens of asthenospermic patients. Each Sample was divided into four equal portions and exposed to a GaAlAs laser beam. Four different doses were administered; no irradiation for the control group, $4 \mathrm{~J} / \mathrm{cm}^{2}, 6 \mathrm{~J} / \mathrm{cm}^{2}$, and $10 \mathrm{~J} / \mathrm{cm}^{2}$. Sperm motility was assessed by means of computer-aided sperm analysis (CASA) at various time intervals, which included immediately following irradiation, 30, 45 and 60 minutes after the intervention, respectively. In order to evaluate the functional capacity of spermatozoids, the aliquots were undergone hypo-osmotic swelling (HOS) test. Besides, sperm DNA fragmentation was assessed through sperm chromatin dispersion (SCD) assay. The two latter tests were performed only on the control group as well as the ones irradiated by $10 \mathrm{~J} / \mathrm{cm}^{2}$ (the highest irradiation dose in this study). Our results indicated that LLLT improved human sperm motility at certain laser density and specific post-exposure time. The semen specimens which received irradiation doses of $4 \mathrm{~J} / \mathrm{cm}^{2}$ and $6 \mathrm{~J} / \mathrm{cm}^{2}$, revealed a significant increase in progressive sperm motility at 60 and 45 minutes following irradiation, respectively. Moreover, results of HOS and SCD tests showed no significant difference between the control group and the samples which received $10 \mathrm{~J} / \mathrm{cm}^{2}$ fluency.

In a similar clinical trial on male infertility, Salama et al. [34] studied the effect of light-emitting diode (LED) on improving seminal quality in subjects with and without asthenospermia. 27 patients were involved in this study. The semen samples were aliquoted into two parts, the ones which exposed to the red LED and the control group. The test tubes were irradiated by LED (wavelength; 636.6-nm) for 2, 5 and 10 minutes. The irradiation doses were calculated as 496 $\mathrm{mJ} / \mathrm{cm}^{2}, 1.241 \mathrm{~J} / \mathrm{cm}^{2}$ and $2.482 \mathrm{~J} / \mathrm{cm}^{2}$ for 2, 5 and 10 minutes, respectively. Sperm kinetics analysis, sperm creatine kinase (CK) activity, aniline blue staining (ANBS), and HOS tests were all evaluated. The CK activity test analyzed the rate of adenosine triphosphate synthesis by spermatozoa, and the aniline blue staining was performed for assessment of the sperm chromatin condensation. The authors indicated a significant increase in the progressive sperm motility among semen specimens irradiated by red LED. In addition, they reported an augmented sperm CK activity in the test tubes. However, the aforementioned results were not statistically significant. Furthermore, they found that treatment with LED could not modify the HOS test and ANBS results compared to the control groups. 
Additionally, low-level laser therapy does have a critical role in improving longevity of spermatozoa in the veterinary practice. In this regard, Laffaldano et al. [35], experimented He-Ne laser irradiation on stored turkey semen samples. Energy dose of $3.96 \mathrm{~J} / \mathrm{cm}^{2}$ was applied and the effect of LLLT on sperm preservation for up to 60 hours has been evaluated. Exposure to this specific dose has significantly enhanced the viability and semen quality in long-term storage compared to the control group. In another study conducted by the same author [36], the efficacy of photobiomodulation on rabbit spermatozoa surveillance during liquid storage conditions has been investigated. The semen pools were divided into four aliquots and irradiated with different energy doses $\left(3.96,6.12,9 \mathrm{~J} / \mathrm{cm}^{2}\right)$ of He-Ne laser. The authors found that the semen samples which were exposed to energy dose of $6.12 \mathrm{~J} / \mathrm{cm}^{2}$ maintained viability after 48 hours of in vitro liquid storage at $15 \circ \mathrm{C}$. A number of relevant research studies on low-level laser therapy were summarized in the table.1, which specifically evaluate the impact of photobiomodulation on seminal parameters in both human and veterinary medicine. 
Table.1. Literature on the effect of photobiomodulation in human and veterinary reproductive medicine.

\section{Author /Ref Irradiation Source $\quad$ Studied Species $\quad$ Interpretation of Results}

Firestone et al.

[37]

Siquiera et al.

[38]

Ban Frangez et al.

[39]

Yeste et al.

[40]

\section{Cohen et al.}

[41]

Abdel- Salam et al.

[42]

\section{Fernandes et al.}

[43]

Laffalando et al.

[22]

\section{Laffalando et al.}

[36]

Laffalando et al.

[35]

\section{Baques et al.}

[44]

Brito et al.

[45]

\section{Sato et al.}

[46]

Baques et al.

[47]

Quero et al.

[48]

Dreyer et al.

[49]
Laser; $905 \mathrm{~nm}$

$1.5 \mathrm{~J} / \mathrm{cm}^{2}$

He-Ne laser, $633 \mathrm{~nm}$

$5.57,10 \mathrm{~mW}$

LED; 470-850 nm

LED; $660 \mathrm{~nm}$

He-Ne laser; $630 \mathrm{~nm}$

Laser, $533 \mathrm{~nm}$

$0.076-0.38 \mathrm{~J} / \mathrm{cm}^{2}$

AlGalnP laser, $660 \mathrm{~nm}$

$4,6 \mathrm{~J} / \mathrm{cm}^{2}$

He-Ne laser

$3.96-9 \mathrm{~J} / \mathrm{cm}^{2}$

He-Ne laser, $660 \mathrm{~nm}$

$3.96-9 \mathrm{~J} / \mathrm{cm}^{2}$
Human

Bull

Human

Boar

Mouse

Bull

Bull

Ram

Rabbit

Increased sperm motility No increase in DNA damage

Increased sperm motility Increased mitochondrial function

Increased sperm motility Decreased immotile sperms

Increased sperm motility Increased sperm viability

Increased $\mathrm{H} 2 \mathrm{O} 2$ generation Increased intracellular $\mathrm{Ca} 2+$

Improvement in semen quality

Increased sperm motility Increased sperm viability Increased acrosome integrity

Increased sperm motility Increased sperm velocity

Increased sperm motility Increased sperm viability Increased acrosome integrity

He-Ne laser Turkey

$0.14-10.8 \mathrm{~J} / \mathrm{cm}^{2}$

Laser; $655 \mathrm{~nm} \quad$ Dog

$4,6,10 \mathrm{~J} / \mathrm{cm}^{2}$

Dog

$6 \mathrm{~J} / \mathrm{cm}^{2}$

Krypton laser; $647 \mathrm{~nm}$

$4,8,32 \mathrm{~J} / \mathrm{cm}^{2}$

Human

Dog

Laser; $655 \mathrm{~nm}$

$3.3418 \mathrm{~J} / \mathrm{cm}^{2}$

$\mathrm{He}-\mathrm{Ne}$ laser; $632 \mathrm{~nm}$

Bull

$2-16 \mathrm{~J} / \mathrm{cm}^{2}$

Bull

He-Ne laser; $633 \mathrm{~nm}$

$150-600 \mathrm{~J} / \mathrm{cm}^{2}$
Increased sperm viability

Increased sperm motility

Increased sperm viability

Increased sperm velocity Increased linear coefficient

No increase in sperm kinetics

Increased sperm motility

Increased sperm motility Increased acrosome reaction

Increased acrosome reaction

Altered DNA methylation 


\section{Effect of laser irradiation on assisted reproduction}

In vitro manipulating of gamete cells to achieve fertilized eggs is the cornerstone of assisted reproductive technology (ART). The laser beam has been implicated in treating both spermatozoa and oocytes prior to intracytoplasmic sperm injection (ICSI). Montag et al. [50], indicated that noncontact, diode laser is an effective procedure for immobilization of human spermatozoa and permeabilization of the sperm tail membrane before ICSI. Similarly, Ebner et al. [51], showed that the spermatozoa samples which were immobilized by laser, required a considerably shorter time for identification, aspiration and injection in comparison to the mechanically immobilized group. Moreover, laser-assisted sperm micromanipulation is a novel approach in the artificial insemination. Obruca et al. [52], used the Er:YAG laser for the subzonal insemination (SUZI). They showed that the laser treated population achieved a significantly higher fertilization rates compared to mechanical SUZI. In addition, sperm viability assessment is regarded as a prerequisite for the intracytoplasmic sperm injection. Laser could be implicated in the selection of viable spermatozoa, especially in the individuals with an indefinite HOS test results [53]. The potential role of laser therapy in handing the oocytes during assisted reproduction, also has been noticed in the recent years. Degeneration of the oocytes in the course of ICSI is an inevitable issue, particularly in the case of fragile oolemma. To mitigate oocyte degeneration associated with microinjection, Abdelmassih et al. [54], applied laser beam to produce a microhole on the zona pellucida of the oocyte. This approach provided a less traumatic penetration into the ooplasm than a microneedle and resulted in much lower cellular degeneration. Rienzi et al. [55], achieved similar results on promoting the oocytes survival rate in the patients with inherent oocyte fragility following ICSI procedure.

The impact of LLLT on oocytes maturation merits consideration. However, there is not sufficient database regarding this issue. Oocytes maturation encompasses a complex of processes resulted in completion of meiosis and subsequent fertilization [56]. Soares et al. [57], investigated the effect of laser therapy on bovine oocyte and particularly the granulosa cells metabolism. During this study the cumulus-oocytes complexes (COCs) were exposed to the laser irradiation with 633-nm wavelength and $1 \mathrm{~J} / \mathrm{cm}^{2}$ fluency. The COCs were evaluated for cell cycle status, mitochondrial functioning, as well as viability. The number of cells progressing through the cycle and mitochondrial membrane potential enhanced significantly. Besides, cyclin B and cyclindependent kinase (CDK4) levels were similarly increased. With regard to the oocytes, there was an escalation in the total mitogen-activated protein kinase along with a decrease in all cell cycle genes transcripts, except the CDK4. In a different experiment, He-Ne laser irradiation at 0.05 and $0.25 \mathrm{~J} / \mathrm{cm}^{2}$ was found to increase the number of unreduced (diploid) oocytes. Concomitantly, oocytes degeneration during the in vitro meiosis was enhanced as well [58]. Likewise, MorenoMillan et al. [59], evaluated the application of He-Ne irradiation in the "in vitro" fertilization. The authors declared that laser therapy at some certain doses triggered oocyte nuclear damage and suppressing oocyte maturation. As mentioned previously the efficacy of LLLT mandates an optimal energy level. Hence, selecting the proper power is a key component in the process of oocyte maturation, and more generally improving the infertility. 


\section{References}

1. Tiphlova O, Karu T. Stimulation of Escherichia coli division by low-intensity monochromatic visible light. Photochem Photobiol. 1988; 48: 467-471.

2. Moneib H, Tawfik AA, Youssef SS, Fawzy MM. Randomized split-face controlled study to evaluate 1550-nm fractionated erbium glass laser for treatment of acne vulgaris-an image analysis evaluation. Dermatol Surg. 2014; 40:1191-1200.

3. Sculean A, Schwarz F, Becker J. Anti-infective therapy with an Er:YAG laser: influence on peri-implant healing .Expert Rev. Med. Devices. 2005; 3: 267-276.

4. Gupta A, Keshri GK, Yadav A, Gola S, Chauhan S, Salhan AK, Bala and Singh S. Super pulsed (Ga-As, $904 \mathrm{~nm}$ ) low-level laser therapy (LLLT) attenuates inflammatory response and enhances healing of burn wounds. J Biophotonics. 2015; 8:489-501.

5. Rangwala S, Rashid, RM. Alopecia: a review of laser and light therapies. Dermatol Online J. 2012; 18: 3.

6. Fioramonti P, Fino P, Ponzo I, Ruggieri M, Onesti MG. Intense pulsed light in the treatment of telangiectasias: case report of Behçet's disease with superficial vascular involvement. J Cosmet Laser Ther. 2014; 16: 124-128.

7. Chen J, Huang Z, Ge M. Gao M. Efficacy of low-level laser therapy in the treatment of TMDs: a meta-analysis of 14 randomized controlled trials. Journal of Oral Rehabilitation. 2015; 42: 291-299.

8. Denadai AS, de Carvalho Pde T, dos Reis FA, Belchior AC, Pereira DM, Dourado DM, et al. Morphometric and histological analysis of low-power laser influence on bone morphogenetic protein in bone defects repair. Lasers Med Sci. 2009; 24:689-95.

9. Wang CZ, Chen YJ, Wang YH, Yeh ML, Huang MH, Ho ML, et al. Low-level laser irradiation improves functional recovery and nerve regeneration in sciatic nerve crush rat injury model. PLOS One. 2014; 9: e103348.

10. Calderhead RG, Kubota J, Trelles MA, Ohshiro T. One mechanism behind LED phototherapy for wound healing and skin rejuvenation: key role of the mast cell. Laser Ther. 2008; 17:141-148.

11. Goralczyk K, Szymańska J, Szot K, Fisz J, Rosc D. Low-level laser irradiation effect on endothelial cells under conditions of hyperglycemia. Lasers Med Sci. 2016; 31:825-831. 
12. Sharlip ID, Jarow JP, Belker AM, Lipshultz LI, Sigman M, Thomas AJ, et al. Best practice policies for male infertility. Fertil Steril. 2002; 77: 873-882.

13. Agarwal A, Mulgund A, Hamada A, Chyatte MR. A unique view on male infertility around the globe. Reprod Biol Endocrinol. 2015; 13: doi: 10.1186/s12958-015-0032-1.

14. Baker K, McGill J, Sharma R, Agarwal A, Sabanegh E. Pregnancy after varicocelectomy: impact of postoperative motility and DFI. Urology. 2013; 81:760-766.

15. Kumalic SI, Pinter B. Review of Clinical Trials on Effects of Oral Antioxidants on Basic Semen and Other Parameters in Idiopathic Oligoasthenoteratozoospermia. Biomed Res Int. 2014; 2014: 426951.

16. Raman JD, Schlegel PN. Aromatase inhibitors for male infertility. J Urol. 2002; 167:624629.

17. Stanic P, Sonicki Z, Suchanek E. Effect of pentoxifylline on motility and membrane integrity of cryopreserved human spermatozoa. Int J Androl. 2002; 25:186-190.

18. Mendeluk GR, Rosales M. Thyroxin Is Useful to Improve Sperm Motility. Int J Fertili Steril. 2016; 10: 208-214.

19. Grassi G, Cappello N, Gheorghe MF, Salton L, Di Bisceglie C, Manieri C, et al. Exogenous platelet activating factor improves the motility of human spermatozoa evaluated with C.A.S.A.: optimal concentration and incubation time. J Endocrinol Invest. 2010; 33:684690.

20. Huang YY, Chen AC, Carroll JD, Hamblin MR. Biphasic dose response in low level light therapy. Dose Response. 2009; 7:358-383.

21. Albuquerque-Pontes GM, Vieira R de P, Tomazoni SS, Caires CO, Nemeth V, Vanin AA, et al. Effect of pre-irradiation with different doses, wavelengths, and application intervals of low-level laser therapy on cytochrome c oxidase activity in intact skeletal muscle of rats. Lasers Med Sci. 2015; 30:59-66.

22. laffaldano N, Paventi G, Pizzuto R, Di lorio M, Bailey JL, Manchisi A, et al. Helium-neon laser irradiation of cryopreserved ram sperm enhances cytochrome $\mathrm{c}$ oxidase activity and ATP levels improving semen quality. Theriogenology. 2016; 86: 778-784. 
23. Passarella S, Marra E, Doonan S, Quagliariello E. Uptake of malate dehydrogenase into mitochondria in vitro. Some characteristics of the process. Biochem J. 1983; 210: 207214.

24. Masha RT, Houreld NN, Abrahamse H. Low-intensity laser irradiation at $660 \mathrm{~nm}$ stimulates transcription of genes involved in the electron transport chain. Photomed Laser Surg. 2013; 31: 47-53.

25. Ferraresi C, Kaippert B, Avci P, Huang YY, Pires de Sousa MV, et al. Low-level laser (light) therapy increases mitochondrial membrane potential and ATP synthesis in C2C12 myotubes with a peak response at 3-6 hours. Photochem Photobiol. 2015; 91: 411-416.

26. Tafur J, Mills PJ. Low-Intensity Light Therapy: Exploring the Role of Redox Mechanisms. Photomed Laser Surg. 2008; 26: 323-328.

27. Griveau JF, Le Lannou D. Influence of oxygen tension on reactive oxygen species production and human sperm function. Int J Androl. 1997; 20:195-200.

28. Lubart R. A New Method for Stimulating the Fertilizing Capability of Sperm Cells. Recent Patents on Biomed Eng. 2009; 2: 193-196.

29. Shahar S, Wiser A, Ickowicz D, Lubart R, Shulman A, Breitbart H. Light-mediated activation reveals a key role for protein kinase $A$ and sarcoma protein kinase in the development of sperm hyper-activated motility. Hum Reprod. 2011; 26, No.9 pp. 22742282.

30. Gadella BM, Luna C. Cell biology and functional dynamics of the mammalian sperm surface. Theriogenology. 2014; 81:74-84.

31. Lubart R, Friedmann H, Sinyakov M, Cohen N, Breitbart H. Changes in calcium transport in mammalian sperm mitochondria and plasma membranes caused by $780 \mathrm{~nm}$ irradiation. Lasers Surg Med. 1997; 21:493-499.

32. Malik Z, Lugaci H. Destruction of erythroleukaemic cells by photoactivation of endogenous porphyrins. Br J Cancer. 1987; 56:589-595.

33. Salman Yazdi R, Bakhshi S, Jannat Alipoor F, Akhoond MR, Borhani S, Farrahi F, et al. Effect of $830-n m$ diode laser irradiation on human sperm motility. Lasers Med Sci. 2014; 29:97-104. 
34. Salama N, El-Sawy M. Light-emitting diode exposure enhances sperm motility in men with and without asthenospermia: Preliminary results. Archivio Italiano di Urologia e Andrologia. 2015; 87: 14-19.

35. laffaldano N, Meluzzi A, Manchisi A, Passarella S. Improvement of stored turkey semen quality as a result of He-Ne laser irradiation. Anim Reprod Sci. 2005; 85:317-325.

36. Iaffaldano N, Rosatoa MR, Paventib G, Pizzutob R, Gambacortaa M, Manchisi A. The irradiation of rabbit sperm cells with $\mathrm{He}-\mathrm{Ne}$ laser prevents their in vitro liquid storage dependent damage. Anim Reprod Sci. 2019; 119: 123-129.

37. Firestone RS, Esfandiari N, Moskovtsev SI, Burstein E, Videna GT, Librach C. The Effects of Low-Level Laser Light Exposure on Sperm Motion Characteristics and DNA Damage. J Androl. 2012; 33: 469-473.

38. Siqueira AF, Maria FS, Mendes CM, Hamilton TR, Dalmazzo A, Dreyer TR, et al. · Effects of photobiomodulation therapy (PBMT) on bovine sperm function. Lasers Med Sci. 2016; $31: 1245-1250$.

39. Ban Frangez H, Frangez I, Verdenik I, Jansa V, Virant Klun I. Photobiomodulation with light-emitting diodes improves sperm motility in men with asthenozoospermia. Lasers Med Sci. 2015; 30:235-240.

40. Yeste M, Codony F, Estrada E, Lleonart M, Balasch S, Pena A, et al. Specific LED-based red light photo-stimulation procedures improve overall sperm function and reproductive performance of boar ejaculates. Sci. Rep. 2016; doi: 10.1038/srep22569.

41. Cohen N, Lubart R, Rubinstein S, Breitbart H. Light irradiation of mouse spermatozoa: stimulation of in vitro fertilization and calcium signals. Photochem Photobiol. 1998; 68:407413.

42. Abdel-Salam Z, Dessouki SH, Abdel-Salam SA, Ibrahim MA, Harith MA. Green laser irradiation effects on buffalo semen. Theriogenology. 2011; 75:988-994.

43. Fernandes GH, Camillo de Carvalho PT, Serra AJ, Crespilho AM, Schatzman Peron JP, Rossato C, et al. The Effect of Low-Level Laser Irradiation on Sperm Motility, and Integrity of the Plasma Membrane and Acrosome in Cryopreserved Bovine Sperm. PLOS ONE. 2015; doi: 10.1371/journal.pone.0121487. 
44. Corral-Baques MI, Rigau T, Rivera M, Rodriguez-Gil JE, Rigau J. Effect of 655-nm diode laser on dog sperm motility. Lasers Med Sci. 2005; 20:28-34.

45. Brito MF, Carvalho TT, Valle GR, Ferreira LFL, Mambrini JVM, Henry RJM, et al. Effect of low intensity red light on the canine semen cryopreservation. Arquivo Brasileiro de Medicina Veterinária e Zootecnia. 2015; 67: 62-70.

46. Sato MH, Landthaler D, Hania D, Schill W-B. The Effects of Laser Light on Sperm Motility and Velocity in vitro. Andrologia. 1984; 16: 23-25.

47. Corral-Baques MI, Rigau T, Rivera M, Rodriguez-Gil JE, Rigau J. The effect of low-level laser irradiation on dog spermatozoa motility is dependent on laser output power. Lasers Med Sci. 2008; doi: 10.1007/s10103-008-0606-7.

48. Ocana-Quero JM, Gomez-Villamandos R, Moreno-Millan M, Santisteban-Valenzuela JM. Biological effects of helium-neon ( $\mathrm{He}-\mathrm{Ne}$ ) laser irradiation on acrosome reaction in bull sperm cells. J Photochem Photobiol B. 199; 40:294-298.

49. Dreyera TR, Perez Siqueirab AF, Magrinia TD, Nichib M, Assumpcaob M, Milazzottoa MP, et al. Low-level laser irradiation-induced changes in bovine spermatozoa. 2014; arXiv: 1406.5234.

50. Montag M, Rink K, Delacretaz G, van der Ven H. Laser-induced immobilization and plasma membrane permeabilization in human spermatozoa. Hum Reprod. 2000; 15: 846852.

51. Ebner T, Yaman C, Moser M, Sommergruber M, Hartl J, Tews G. Laser assisted immobilization of spermatozoa prior to intracytoplasmic sperm injection in humans. Hum Reprod. 2001; 16: 2628-2631.

52. Obruca A, Strohmer H, Sakkas D, Menezo Y, Kogosowski A, Barak Y, et al. Use of lasers in assisted fertilization and hatching. Hum Reprod. 1994; 9:1723-1726.

53. Gerber PA, Kruse R, Hirchenhain J, Krussel JS, Neumann NJ. Pregnancy after laserassisted selection of viable spermatozoa before intracytoplasmatic sperm injection in a couple with male primary cilia dyskinesia. Fertil Steril. 2008; doi: 10.1016/j.fertnstert.2007.06.012. 
54. Abdelmassih S, Cardoso J, Abdelmassih V, Dias JA, Abdelmassih R, Nagy ZP. Laserassisted ICSI: a novel approach to obtain higher oocyte survival and embryo quality rates. Hum Reprod. 2002; 17: 2694-2699.

55. Rienzi L, Greco E, Ubaldi F, lacobelli M, Martinez F, Tesarik J. Laser-assisted intracytoplasmic sperm injection. Fertil Steril. 2001; 76:1045-1047.

56. Albertini DF, Carabatsos MJ. Comparative aspects of meiotic cell cycle control in mammals. J Mol Med (Berl). 1998; 76:795-799.

57. Soares CA, Annes K, Dreyer TR, Magrini T, Sonoda MT, da Silva Martinho H, et al. Photobiological effect of low-level laser irradiation in bovine embryo production system. $J$ Biomed Opt. 2014; 19: 35006.

58. Ocana-Quero JM, Gomez-Villamandos R, Moreno-Millan M, Santisteban-Valenzuela JM. Helium-Neon ( $\mathrm{He}-\mathrm{Ne}$ ) laser irradiation increases the incidence of unreduced bovine oocytes during the first meiotic division in vitro. Lasers Med Sci. 1998; 13: 260-264.

59. Millan H. Ocana Quero JH. Preliminary results of the evaluation of the use of clinical laser $\mathrm{He}-\mathrm{Ne}$ radiation in the process of bovine "in vitro fertilization" Bulletin UASVM, Veterinary Medicine. 2009; 66:495. 